\title{
TREATMENT OF SUBACUTE INFECTIVE ENDOCARDITIS WITH HEPARIN AND CHEMOTHERAPY
}

\author{
BY \\ W. TREVOR COOKE AND A. BRIAN TAYLOR \\ From the Birmingham United Hospital
}

Received June 14, 1943

The incidence of bacterial endocarditis in rheumatic heart disease has been reported by various workers to be between 4 and 17 per cent, while in congenital heart disease it is between 14 and 22 per cent. The condition has been regarded by most physicians as uniformly fatal, though undoubtedly some mild and a few severe cases occasionally recover as Libman (1934) and Hamman (1937) have pointed out. By examining only reported series of cases of infective endocarditis treated by non-specific means, Lichtman and Bierman (1941) found that 6 out of $634 \mathrm{had}$ undergone spontaneous cure. There are also reports of small epidemics of apparently proven cases in which the recovery rate has been high (Oille, Graham, and Detweiter, 1915, 1924, and Salus, 1920). Since the introduction of the sulphonamide drugs, there have been many reported cures and consequently a great revival of interest in the diagnosis and treatment of this condition. Having observed the successful cases reported by Kelson and White (1939) treated with sulphapyridine and heparin, we undertook this investigation, primarily to study the combined method of therapy with heparin and sulphonamides.

The lesion is a focus of relatively avirulent organisms enclosed in a mass of platelets and fibrin on a damaged valve. In 90-95 per cent of cases, the organisms are of the Streptococcus viridans type. The method by which they form these foci is debated: they may be embolic in the damaged valve or deposited on the surface with the platelet thrombi. Von Glahn and Pappenheimer (1935) have suggested that the lesions are grafted on to an active rheumatic endocarditis in most cases. The blood of these patients contains a very high antibody titre against the infecting organism and this factor alone tends to localize any transient bacteræmia. The platelet thrombi thus provide an ideal nidus for bacterial proliferation, providing as they do an excellent barrier from the bacteriocidal action of the blood, and situated upon a tissue that has the most sluggish reaction in the body, because there is minimal blood vessel and leucocyte invasion in the damaged valves. The infection is able to continue in the valve only if the deposition of fibrin exceeds the rate of invasion of leucocytes and it is upon this balance that the ultimate fate of the patient depends. Treatment will therefore depend upon either preventing the further deposition of fibrin or killing the organism by methods such as chemotherapy.

\section{HePARIN AND ChEMOTHERAPY}

Friedman, Hamburger, and Katz (1939) tried the first concept by using continuous intravenous heparin to bring about a prolongation of the clotting time during a period of two weeks or more and so slowing the deposition of fibrin. Since their original report some 5 cases at least have been treated and all have died. Kelson and White (1939) combined both concepts of treatment and reported 4 cases cured out of a total of 7 treated. This combined therapy has now been given to more than 70 reported cases of which 7 have survived. Such treatment, however, is not without danger. The risks of continuous intravenous therapy in 
seriously ill patients for a period of fourteen days are considerable. The increased fluidity of the blood carries with it still more dangers. Cerebral hæmorrhage and cerebral emboli have been attributed to the prolonged clotting time, and Kleiber (1940) and Witts (1940) have reported renal hæmorrhage. All these complications can occur without any therapy, and it may be difficult to prove statistically that there is any increased risk in the use of heparin. In our Case 5, we considered that the patient's death was directly due to heparin. Prior to therapy his condition had been good, his clotting time had been markedly prolonged by heparin, and his temperature adequately controlled by sulphapyridine; and at autopsy the vegetation was small and suggested that healing was taking place: however, he died suddenly of cerebral hæmorrhage whilst under treatment. In most reported cases, fairly adequate prolongation of the clotting time was obtained. In four of our cases it seemed inadequate in spite of using the doses of heparin recommended. Some of the preparations used appeared to be lacking in potency (cf. Petch, 1940). It is difficult to believe, in the absence of experimental proof, that healing of the lesion could take place in the short space of two weeks. It is also fair comment that no case has yet been reported cured by the use of combined therapy in which complete control of the infection had not already been attained by chemotherapy alone, so that the role of heparin becomes extremely difficult to evaluate. At present, opinion is against the further use of heparin as now administered because the dangers appear to outweigh the uncertain advantages.

Case 1. A man, aged 22, was admitted complaining of cough, palpitation, and sweating of five weeks duration. On examination, he had mitral and aortic valvular disease, an enlarged spleen, petechiæ, and red cells in the urine. The blood culture was positive for $S$. viridans. His temperature varied between $101^{\circ}$ and $102^{\circ} \mathrm{F}$. He had a moderate degree of anæmia. Chemotherapy (sulphapyridine $45 \mathrm{~g}$. during the first 13 days followed by $62 \mathrm{~g}$. and prontosil $60 \mathrm{~g}$. over the next 24 days) caused an immediate reduction of his temperature. On the seventh day, intravenous heparin in saline was given (750,000 units in 10 pints normal saline over seven days). No definite effect upon the clotting time was noted. He died five weeks after this and two weeks after stopping chemotherapy, in congestive failure. There was no autopsy.

No adequate deductions can be made from this case. He probably died from rheumatic carditis with the infective process temporarily controlled by the chemotherapy. There does not appear to be any evidence that the heparin played any role in the maintaining of normal temperatures or indeed that it exerted any action at all in the dosage given. The extra fluid may have played some part in the subsequent congestive failure. A normal temperature is not infrequently seen in the terminal stages of this disease.

Case 2. A man, aged 30, was admitted on 13/10/39 complaining of pyrexial attacks and general malaise following dental extraction five months previously. Examination showed a good general condition, clubbed fingers, and signs in the heart of a patent ductus arteriosus. Blood cultures grew S. viridans. The temperature varied between 97 and $101^{\circ} \mathrm{F}$. After two short trials of chemotherapy with immediate control of the pyrexia, sulphapyridine was given for one month. Blood cultures became negative immediately and on the ninth day, intravenous heparin in saline $(1.6 \mathrm{~g}$. in 23 pints of saline in 10 days) was given. Only slight prolongation of the clotting time, from 5 to 15 minutes, was obtained. The temperature remained normal for eight weeks apart from one episode of chest pain suggestive of a pulmonary embolus. Following a severe hæmolytic streptococcal throat, he again began to run a high temperature. Prolonged chemotherapy (101 g. over five weeks) again brought about a remission. During this period the remainder of his septic teeth were extracted and a number of blood cultures were negative. The patient felt well and had put on weight whilst his blood count had risen to over four million. He left hospital in May, 1940.

Nothing further was seen of him in spite of repeated requests until he was again readmitted. He had worked for six months on a light job, but two months prior to admission, had had a recurrence of all his previous symptoms. Examination showed the typical café-au-lait colour, splenomegaly, and Osler's nodes, while the heart showed in addition to the original lesion, signs suggesting involvement of the aortic and the mitral valves. Blood cultures were again positive for $S$. viridans and the pyrexia varied between $99-101^{\circ} \mathrm{F}$. Chemotherapy was again started and $150 \mathrm{~g}$. sulphapyridine were administered over 45 days. The temperature was fairly well controlled on this regime, only occasional temperatures of $99-100^{\circ}$ being observed: the white cells were not depressed in spite of a moderate degree of anæmia ( 2.6 million). At first it seemed that a further remission would be induced, but after four weeks his condition began to deteriorate and chemotherapy was subsequently 
stopped. He was discharged home and died three days later, about two years after the onset of his illness. There was no autopsy.

Here, the onset appeared to be precipitated by his dental extractions and the source of the infection may have been there. Sulphapyridine was probably the main factor in producing the good remission that he had early in his illness. Heparin had very little part and very little effect in prolonging the clotting time. In addition to his congenital heart lesion, he presented symptoms and signs suggestive of active rheumatism, involving the heart and especially the aortic valves. If such was the case, he was probably more liable to a flare up of the infective process. We considered that this patient's life was prolonged by the treatment.

Case 3. A girl, aged 19, was admitted $27 / 3 / 40$, complaining of shortness of breath and swelling of her joints. Examination showed petechiæ, a mitral systolic murmur and thrill, and an early diastolic murmur at the aortic area. Her temperature varied between 101 and $103^{\circ} \mathrm{F}$. Blood cultures were positive for $S$. viridans. Sulphapyridine brought about an immediate reduction in her temperature and after $40 \mathrm{~g}$. had been given, it was discontinued, with an immediate reversion of her temperature to the previous levels. One week later, chemotherapy was again instituted and again the temperature was controlled. After $50 \mathrm{~g}$. had been given over 9 days, the white cells fell to 400 . She reacted well to blood transfusions and the fortuitous occurrence of an abscess of the buttock. Following her recovery, her condition remained unchanged for the next five weeks. A further $32 \mathrm{~g}$. was given without any ill effects upon the white cells but after five days, the pyrexia reappeared. A further course of $16 \mathrm{~g}$. had no effect at all upon the temperature. On 12/7/40, chemotherapy was again started in adequate doses with control of the temperature, and on the seventh day intravenous heparin in normal saline was given $(2.25 \mathrm{~g}$. in 15 pints of normal saline over 150 hours). On the third day, however, splenic infarction occurred, and the following day she developed signs at the left base with recurrence of temperature and general deterioration; heparin was accordingly stopped. Chemotherapy was continued for two further periods, 51 and $70 \mathrm{~g}$. being given, with only slight control of the temperature. Her condition during this period deteriorated only slowly. Eventually five months after admission she went into coma and died, having during this time received $270 \mathrm{~g}$. of sulphapyridine.

Autopsy showed numerous infarcts in lungs, kidneys, and brain. The heart weighed $560 \mathrm{~g}$. with extensive vegetations on the mitral, aortic, and tricuspid valves.

Chemotherapy may have played a part in prolonging the life of this patient. Heparin had no effect except in the possible production of emboli. Again one failed to effect adequate prolongation of the clotting time with the doses of heparin that were given. Following agranulocytosis, further chemotherapy was not given without trepidation, but there was no reduction of the white cells in spite of the full doses of sulphapyridine, $182 \mathrm{~g}$. in all. At first the organism seemed to be susceptible to the drug but eventually became resistant. The experience in this case made us persevere with more continuous chemotherapy.

Case 4. A man, aged 41. Eight months previously he had begun to run intermittent temperatures following a sore throat, gradually losing weight and developing malaise. He had had numerous small hæmoptyses. For the past five months he had been continuously in bed. Examination showed a very ill man with signs of aortic and mitral disease, splenomegaly, clubbed fingers, and a high swinging temperature. Blood cultures were positive for $S$. viridans. Whilst in hospital, he had a number of attacks of paroxysmal auricular fibrillation. His temperature responded immediately to chemotherapy and on the sixth day intravenous heparin and saline was started $(1.5 \mathrm{~g}$. in 4 pints of normal saline over six days). No prolongation of clotting time beyond 21 minutes was obtained, his normal being four minutes. On this therapy he deteriorated rapidly and began to run a temperature. He was allowed home, still taking sulphapyridine, and died a few days later. There was no autopsy.

This patient was already seriously ill when therapy was started and his course did not appear to be influenced in any way.

Case 5. A man, aged 36, was admitted, complaining of pyrexial attacks and malaise following dental extraction four months previously. Examination showed a mitral systolic murmur and thrill, finger clubbing, petechiæ, and splenomegaly. Blood cultures were positive for $S$. viridans. His temperature varied between 99 and $101^{\circ} \mathrm{F}$. In spite of these findings, his general condition was good. Sulphapyridine was started with an immediate reduction of temperature. Owing to nausea and vomiting, a concentration greater than $9.9 \mathrm{mg}$. per 100 c.c. was never attained, the average being about $5 \mathrm{mg}$. On the seventh day heparin in saline was given intravenously $(8.25 \mathrm{~g}$. in 16 pints over 13 days). Satisfactory prolongation of the clotting times was achieved, up to 60 minutes. 
There was an immediate rise of temperature with the intravenous therapy which settled again in two days. His blood count fell from four million to two and a half, and his condition which had been good began to deteriorate rather rapidly. He died suddenly from cerebral hæmorrhage on the thirteenth day of intravenous therapy.

Autopsy showed extensive cerebral hæmorrhage with previous emboli and extensive retroperitoneal hæmorrhage. The heart showed a small vegetation on the mitral valve less than $\frac{1}{4}$ inch long. Microscopical section of the valve and vegetation showed much fibroblastic activity and giant cell formation.

We considered that the death of this patient was almost directly due to heparin therapy and that had chemotherapy alone been employed, he would have had an excellent chance of surviving. As a consequence of the experience of this and the other cases, we were reluctant to submit further patients to the combined therapy before we had made an extensive trial of chemotherapy alone.

\section{CHEMOTHERAPY ONLY}

The second aspect of therapy is that of exerting bacteriostatic or bacteriocidal influences upon the organisms themselves. Innumerable substances have been administered by mouth, subcutaneously, and intramuscularly, without any effect until the sulphonamide group of compounds was tried, though Osgood (1942) has recently claimed good results from a modified treatment with neoarsphenamine. Experimentally it is difficult to show how the sulphonamides have produced these cures. Friedman (1941) has shown that sulphapyridine has little penetrating power into the fibrin barrier round the focus of bacteria. He reported unsuccessful results in 12 cases and concluded as a result of his experimental and clinical findings that chemotherapy was of no avail. Duncan and Faulkner (1941) confirmed these experimental findings but they showed in addition, that the sulphonamide derivatives would be included in the clot if they were given prior to the formation of the clot. The number of reported cures supports this observation and should refute Friedman's statement and Katz (1941) belief that no case has ever been cured by chemotherapy. Since the bacteriocidal power of the blood is already adequate to deal with any organism liberated but not with the source of the organisms themselves, the suggestion put forward by Duncan and Faulkner that the drugs act by being incorporated in the clot seems to be the most logical and probable mechanism.

Lichtman and Bierman (1941) found that 12 out of 200 reported cases of subacute infective endocarditis had recovered. They also pointed out that of 45 cases treated with hyperpyrexia in addition, 9 recovered. Such figures, though not dramatic and probably from rather selected series with milder cases, do offer some improvement upon the era before chemotherapy. Indeed, Graybiel and White (1942) suggest that it is now probable that one case in twenty recovers.

During the past three years, we have observed 20 cases (including the 5 to whom heparin was also given) to whom the sulphonamide group of derivatives was given in adequate doses. Of these, 5 were totally unresponsive to either sulphathiazole, sulphapyridine, or sulphonamide; 12 cases were moderately controlled with temporary antipyretic effect, and 3 showed complete remission of the pyrexia. Case 1 received sulphonamide for 37 days apparently with complete control of the infection before dying of congestive failure. It is difficult, however, to draw any conclusions from this case. Case 6 was completely relieved of his symptoms but died a year after the onset of his infection, with congestive heart failure. Case 7 has now been apyrexial for seven months and has had a normal sedimentation rate for five months.

Case 6. A man, aged 21, was admitted complaining of general malaise and high temperature for 13 weeks. He had had chorea when 4 and probably acute rheumatism when 18 . He had been otherwise well and active.

Examination showed a pale but fairly well-built man with early finger clubbing. There was a systolic murmur at the apex and a marked musical diastolic murmur at the base. The tip of the spleen was just palpable. There was no petechiæ. Three blood cultures were negative. An X-ray examination of the heart did not show any enlargement. 
For the first ten days in hospital he ran an irregular temperature to $102^{\circ} \mathrm{F}$. With the administration of sulphapyridine ( $6 \mathrm{~g}$. daily), the temperature fell to normal on the third day. For the next 8 months, only on three occasions did the temperature reach $99^{\circ} \mathrm{F}$. Four days after starting therapy, he developed pain in the left hypochondrium and the spleen became more easily palpable. This disappeared after two days and was not felt again. After one month, the dose of sulphapyridine was halved to $3 \mathrm{~g}$. daily and this dosage was continued for seven months, a total of $730 \mathrm{~g}$. being given without any nauseating or obviously deleterious effects.

The sedimentation rate fell from $38 \mathrm{~mm}$. per hour (Westergren) on starting therapy to $6 \mathrm{~mm}$. per hour after six weeks and remained below this until his final illness.

His blood count gradually rose to 4,700,000 red cells (from 4.1), to 94 per cent hæmoglobin (from 80 ), and to 7500 white cells. His white blood cells count fell to 4900 on one occasion, but usually remained between 5500 and 6000 , the polymorphs averaging 60 per cent.

He was discharged from hospital for further convalescence 14 weeks after admission. The only

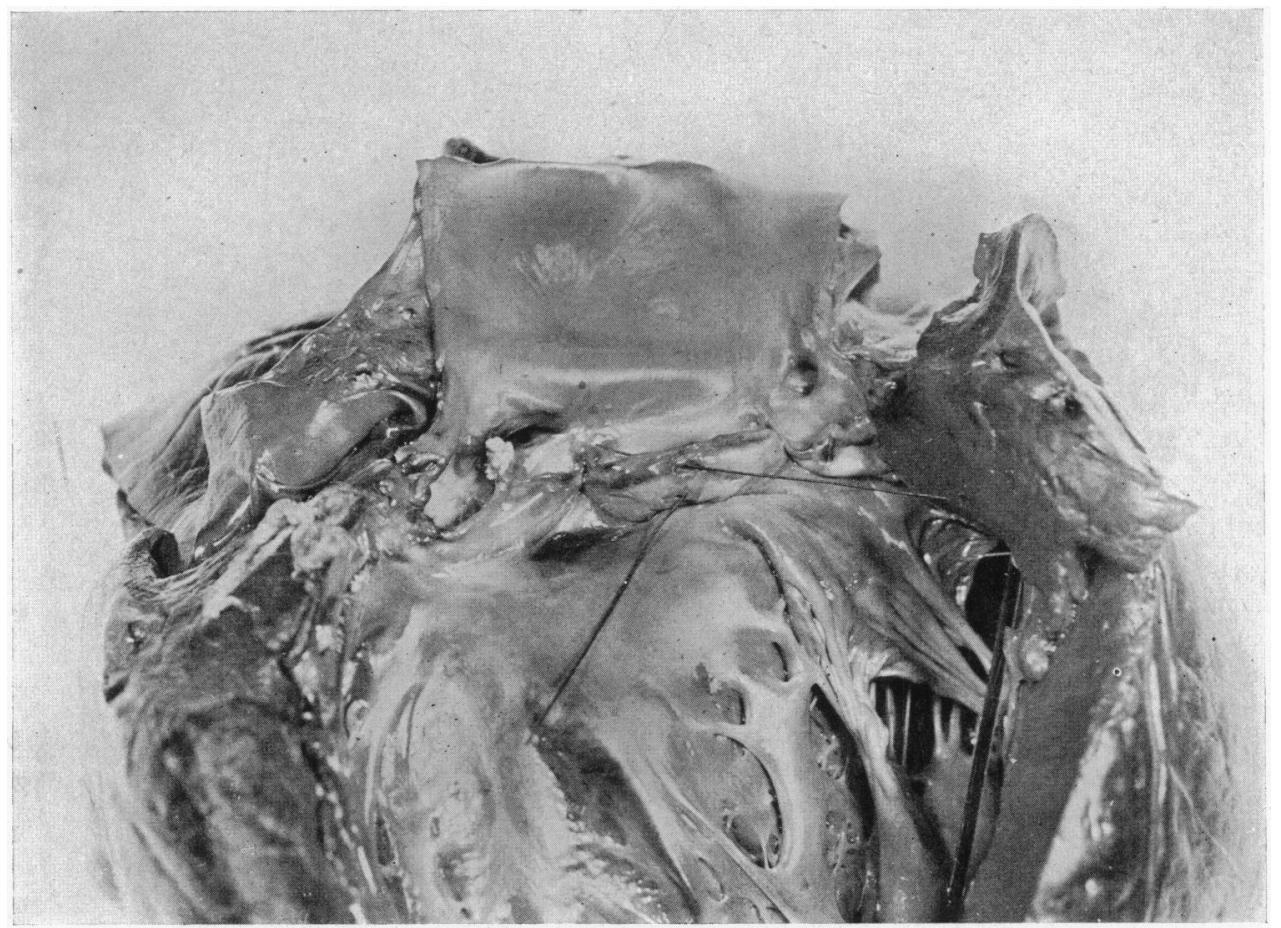

FIG. 1.-Interior of the left ventricle showing the aortic valves with two perforations, through which fibres have been passed. The endocardium round these perforations is well healed. The calcified vegetation is seen on the adjacent cusp. All three cusps show evidence of chronic rheumatic endocarditis.

disquieting feature was mild anginal pain on exertion, and a rapid pulse rate varying between 95 and 100. Over the next few months, he was seen regularly and it was noted that his heart was gradually enlarging. In spite of this, he felt well and was able to start work for a few hours daily as a laboratory technician. Unfortunately at the end of his first week he developed a severe cold and sore throat. Two weeks later he was readmitted with congestive failure, marked jaundice, and signs of consolidation at both bases. He died three days after admission.

Autopsy. Pleural cavities, a large amount of straw-coloured fluid. Lungs, both congested and œdematous with diffuse bilateral bronchopneumonia. Heart, enlarged and dilated, weighing $590 \mathrm{~g}$. Left auricle, normal; left ventricle hypertrophied and dilated, with incompetence of the mitral valve and some thickening and shortening of the chordæ tendinæ. Aortic valve (Fig. 1) incompetent, the edges thickened. On edge of right cusp a pedunculated and calcified vegetation. Left cusp, two small perforations with healthy endocardium round them. Right ventricle, dilated and hypertrophied; right auricle, normal. Liver, congested. No evidence of perisplenitis or old infarcts in the spleen. Kidneys, a few typical healed scars of old infarcts.

Microscopical examination. Heart muscle showed considerable interstitial fibrosis. No Aschoff's bodies were seen. Sections through the calcified vegetation showed complete covering with endocardium (Fig. 2 and 3) with no evidence of any bacteria or inflammatory reaction. Sections through the two perforations of the valves also confirmed the diagnosis of healed infective endocarditis. Sections of the lungs showed diffuse bronchopneumonia with polymorphonuclear infiltration. The kidneys appeared to be normal except for the signs of congestion. 


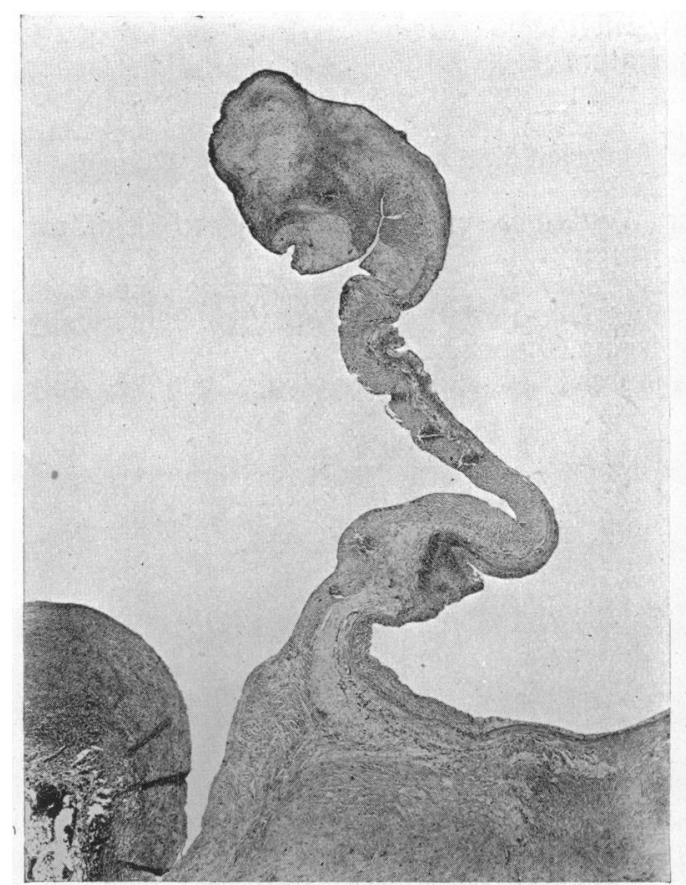

A

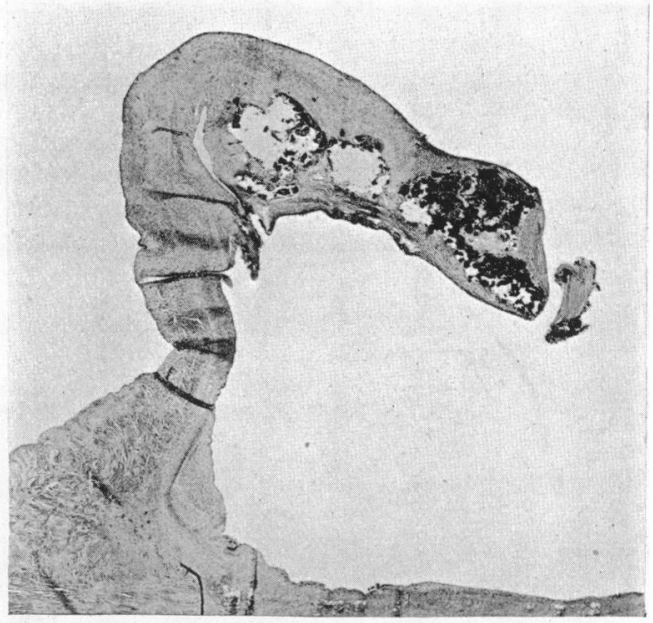

B

FIG. 2.-(A) Section through the central cusp passing through the edge of the two perforations. Magnification $\times 11 \cdot 7$. (B) Section through the base of the calcified vegetation and the valve cusp, showing the extensive calcification. Magnification $\times 10 \cdot 8$.

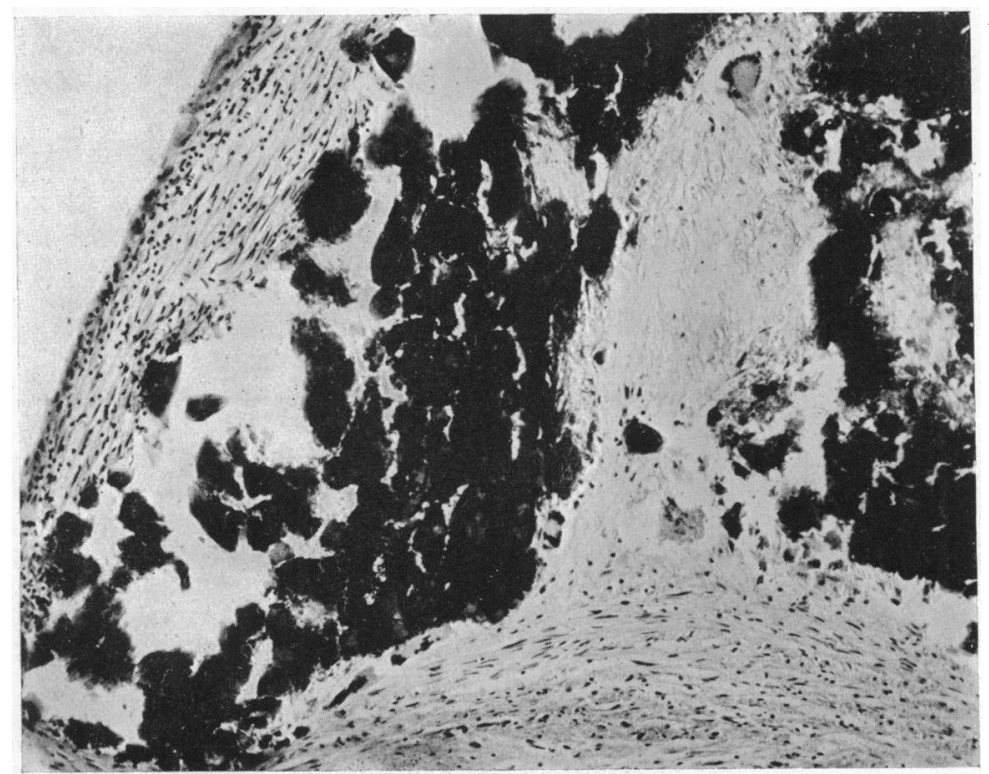

FIG. 3.-Section as in (B) showing the tip under high power. A number of foreign body giant cells can be seen round the edge of the calcification. There is a good endocardial covering and no evidence of any polymorphonuclear or lymphocytic infiltration in the extensive fibrous tissue. Magnification $\times 100$. 
This patient was able to take over $700 \mathrm{~g}$. of sulphapyridine during seven months of therapy, showing no obvious deleterious effect and maintaining a good appetite the whole of the time. Examination of the sections of the heart valves showed that he had indeed been cured, but that the damage wrought upon the aortic valve had thrown too great a strain upon the myocardium and caused his death. This possibility is always present, so that even though the infection is cured, the residual lesion may be sufficient to kill the patient or cause him to be a permanent invalid. There are, however, an adequate number of reported cured cases who are earning their living, enough to indicate that the majority do attain a fair degree of recovery. There was no evidence of myocarditis in the sections such as has been reported by French and Weller (1942) following the use of the sulphonamide drugs.

Case 7. A milk-roundsman, aged 29, was admitted to hospital, complaining of pain in the left side and in the back of two weeks' duration. He had had rheumatic fever at the age of 18 for fifteen weeks, since followed by intermittent pains and swelling of his joints. Over the previous ten months he had noticed some shortness of breath and lassitude, insufficient, however, to keep him from his work. Ten weeks prior to admission, he had severe pain in his back for four days. Four weeks later, he had a severe cold and sore throat. Following this, he had severe soaking night sweats and began to feel really ill. Two weeks prior to admission, he again developed pain in the back and left loin which persisted until admission.

Examination showed a fairly well built man with a slight café-au-lait coloration, marked finger clubbing, and slight clubbing of the toes. There were no nodules or petechiæ. His teeth were grossly infected and carious. The heart was not enlarged. The mitral first sound was accentuated with a loud rough systolic murmur and thrill and soft mid-diastolic murmur. The sounds at the aortic area were normal. His blood pressure was 120/85. The spleen was just palpable. The urine contained a cloud of albumen, fatty and hyaline casts, and occasional red cells. His blood count was red cells 4,320,000 hæmoglobin 78 per cent and white cells 9150 with 75 per cent polymorphonuclears. The blood cultures showed 12 and 5 colonies per c.c. of $S$. viridans. His sedimentation rate was $81 \mathrm{~mm}$. per hour (Westergren method). His temperature varied between $98^{\circ}$ and $102^{\circ} \mathrm{F}$. On commencing sulphapyridine ( $6 \mathrm{~g}$. daily), his temperature fell to $99^{\circ} \mathrm{F}$. As a normal temperature had not been produced in nine days, three injections of intravenous T.A.B. vaccine was given on alternate days. Followịng a moderately good reaction, his temperature became normal and has remained normal since except for three further T.A.B. injections given six weeks later. Slight nausea but no vomiting was produced by the sulphapyridine during the first five days, but thereafter he was able to take the drugs without any discomfort. After ten days, the dosage was reduced to $4 \mathrm{~g}$. daily and on this dosage he maintained a blood stream concentration of sulphapyridine varying between 14 and $21 \mathrm{mg}$. per 100 c.c. His white cells never fell below 8500, his average count being 10,000 with 55 per cent polymorphs. His septic teeth were extracted in the sixth week of therapy and he was allowed to sit out of bed at the end of the ninth week. At this stage his pulse varied between 90 and 100 beats per minute while his sedimentation rate had dropped to $6 \mathrm{~mm}$. per hour.

He was finally discharged at the end of his fourteenth week of therapy to a convalescent home, having put on two stone in weight whilst in hospital. Sulphapyridine was continued with two grams daily for a further four weeks. In all he took $400 \mathrm{~g}$. of sulphapyridine without any ill effects. At present, he looks extremely fit, has some dyspnœa on moderate exertion, but is without any signs of bacterial endocarditis and his sedimentation rate is normal.

This patient appears to have attained a complete remission from his infection. He is still limited in his activities by his mitral stenosis. The consistently high blood levels of sulphapyridine may have played some part in his recovery. It was also of interest to note that his temperature only fell to normal after intravenous T.A.B. vaccine as advocated by Soloman (1941). We are not, however, inclined to attribute any definite role to this treatment as a factor in his recovery. At no time during chemotherapy did we experience any anxiety about the effect upon the white cells or kidneys.

Of the twelve cases that made some response to chemotherapy, all eventually became resistant and died. None of them took the drugs without showing much nausea, necessitating discontinuance of therapy in some cases even though there seemed to be some control of the infection. These toxic manifestations are the chief difficulty in the treatment and frequently prevent adequate concentration of the drug in the blood stream. One of these cases received sulphapyridine, sulphadiazine, and sulphathiazole in succession, $340 \mathrm{~g}$. in all over nine weeks without a successful result although the temperature was fairly well controlled. There was, 
however, much nausea and intolerance to the drugs and concentration above $6 \mathrm{mg}$. per 100 c.c. was not attained. In such cases, even if there is not complete control of the infection, it is felt that prolonged therapy is justified in view of the experience reported by Heyman (1940) in which some weeks elapsed before the patient became afebrile and eventually obtained a complete cure.

Agranulocytosis was encountered once (Case 2) but this responded well to therapy. Subsequent chemotherapy was controlled by white cell counts on alternate days, the leucocytes remaining consistently between 7000 and 10,000. Only a few cases of agranulocytosis have been reported, e.g. Leach et al. (1941) and Rinkoff and Spring (1941). Smith, Sauls, and Stone (1942) gave $894 \mathrm{~g}$. of sulphanilamide in 73 days of continuous therapy to one of their patients who had been fit and well at the time of the report for 29 months. Thomas (1942) in considering the dangers of agranulocytosis in prolonged therapy in the prophylaxis of rheumatic fever, pointed out that in no instance had any toxic effects been seen after the first few weeks of treatment and that agranulocytosis had never been observed after the fiftieth day of chemotherapy given for any condition. We agree that the risks of chemotherapy are slight and in view of the seriousness of the disease being treated, that they may be neglected though routine weekly counts should be made.

In an effort to minimize the nauseating effect of the drugs, they have been administered in a mixture containing sulphapyridine or its equivalent $1 \mathrm{~g}$., citric acid $\frac{1}{2} \mathrm{~g}$., nicotinic acid $25 \mathrm{mg}$., mucilage q.s., aq. menth. pip. ad. $\frac{1}{2}$ oz. For the first few weeks of therapy, this was always given with food or milk. Ascorbic acid $300 \mathrm{mg}$. daily was also given in some cases including Cases 6 and 7, primarily to counteract the deficiency induced by any prolonged infection. Recently, however, Thompson (1942) has shown that ascorbic acid under experimental conditions markedly diminishes the toxic effects of sulphapyridine probably through its oxidizing properties. Vitamin A, 5000 units, and Vitamin D, 1000 units, were also administered daily to most patients.

The persistence of a slight temperature in some cases may well be due to the presence of active rheumatic fever. It is important therefore that prolonged rest in bed should be employed in any case where it seems likely that cure is probable, in order to allow the heart to recover as fully as possible from the serious infection to which it has been subjected. Even so, as we have pointed out above, the case may proceed to a fatal termination as in Kelson and White's Case 1 and our Case 6. Occasionally, as Jones and Bland (1939) have pointed out, the sulphonamide drugs may cause a fatal relapse in rheumatic myocarditis. The temperature may also be due partly to the drug itself. In one of our cases which eventually died and in Case 4 of Leach et al. this appeared to be so.

The evaluation of any therapy in infective endocarditis is made difficult by the uncertainties of diagnosis. In a patient with pyrexia, the presence of three out of four criteria, a valvular murmur, splenomegaly, positive blood cultures, or embolic phenomena, are usually accepted as sufficient evidence. The only absolute proof, however, is the presence of the lesion at autopsy. The diagnosis in Case 6 was confirmed at autopsy and Case 7 showed all four of the criteria usually accepted for the diagnosis. In early or mild cases, these criteria may not be fulfilled, and in such cases with recovery, cure cannot be claimed. These difficulties were well illustrated by one further case.

A woman, aged 26, was admitted with repeated hæmoptyses and slight pyrexia. Examination showed a pale sweating woman with signs of mitral stenosis. Whilst under observation she had repeated episodes of chest pain and hæmoptysis, and began to run a high swinging temperature. At the same time, she developed an aortic diastolic murmur and a collapsing pulse. Repeated blood cultures were negative. She showed no response to salicylates. Some control of the temperature was obtained with sulphthiazole, but after $45 \mathrm{~g}$. had been given as her condition appeared to be deteriorating, she was taken home by her relatives. Now, 15 months later, she has a normal temperature but still an occasional hæmoptysis. The diagnosis of infective endocarditis therefore has been revised and it is considered that acute rheumatic carditis explained the whole illness. 


\section{SUMMARY AND CONCLUSIONS}

Five cases were treated with combined chemotherapy and intravenous heparin. All died, and in one this was probably due to the heparin therapy.

Twenty cases (including the five treated with heparin) were studied under treatment with sulphonamide derivatives. Five were totally unresponsive, twelve were moderately controlled. Life was prolonged in some but all eventually died. Three cases became apyrexial; one died after 45 days of normal temperature, but as there was no autopsy, neither the diagnosis nor the state of the lesion could be determined. A second died one year after the onset of his infection and eight months after the control of his pyrexia by sulphapyridine: autopsy showed healed lesions of infective endocarditis. The third is well and working at his occupation as a milk-roundsman, at the present time, now twelve months after his discharge from hospital.

Intravenous heparin did not prove of value in our cases and, as others have found, should not be used in these cases.

Prolonged chemotherapy offers a chance of cure to a few patients though the great majority will not be so benefited. The dangers of such prolonged therapy are small and should not weigh against the chances of a successful outcome.

We wish to thank the Physicians of the Birmingham United Hospital for permission to study these cases. The cost of heparin was defrayed by a grant from the Medical Research Council.

\section{REFERENCES}

Duncan, C. N., and Faulkner, J. M. (1940). Amer. J. med. Sci., 200, 492.

Friedman, M. (1941). Arch. intern. Med., 67, 921.

Friedman, M., Hamburger, W. W., and Katz, L. N. (1939). J. Amer. med. Ass., 113, 1702.

Hamman, L. (1937). Ann. intern. Med., 11, 175.

Heyman, J. (1940). J. Amer. med. Ass., 114, 2373.

Jones, T. D., and Bland, E. F. (1939). Personal Communication.

Katz, L. N. (1942). Arch. intern. Med., 69, 746.

Kelson, S. R., and White, P. D. (1939). J. Amer. med. Ass., 113, 1700.

Kleiber, E. E. (1940). Ibid., 115, 1713.

Leach, C. E., Faulkner, J. M., Duncan, C. N., McGinn, S., Porter, R. R., and White, P. D. (1941). Ibid., 117, 1345 .

Libman, E. (1934). Modern Concepts of Cardiovascular Disease, 3, 6.

Lichtman, S. S., and Bierman, W. (1941). J. Amer. med. Ass., 116, 286.

Oille, J. A., Graham, D., and Detweiter, H. K. (1915). Trans. Ass. Amer. Phys., 30, 674. (1924). Ibid., 39, 227.

Osgood, E. E. (1942). Arch. intern. Med., 69, 746.

Petch, C. P. (1940). Lancet, 2, 637.

Rinkoff, S. S., and Spring, M. (1941). Ann. intern. Med., 15, 89.

Salus, G. (1920). Med. Klin. Berl., 16, 1107.

Smith, C., Sauls, H. C., and Stone, C. F. (1942). J. Amer. med. Ass., 119, 478.

Thomas, C. (1942). Bull. N. Y. Acad. Med., 18, 508.

Thompson, M. R. (1942). Arch. intern. Med., 69, 662.

Von Glahn, W. C., and Pappenheimer, A. M. (1935). Ibid., 55, 175.

Witts, L. J. (1940). Brit. med. J., 1, 484. 